\title{
Polysulfone Membranes With Embedded Palladium Nanoparticles for Catalytic Reduction of 4- nitrophenol
}

\section{Rapelang Patala}

Nomcebo P Khumalo

Hlengilizwe Nyoni

Bhekie Brilliance Mamba

Dan Liu

Jianzhou Gui

Alex Tawanda Kuvarega ( $\nabla$ kuvarat@unisa.ac.za )

University of South Africa - Science Campus https://orcid.org/0000-0002-7452-0442

\section{Research Article}

Keywords: Polysulfone, phase inversion, water flux, 4-nitrophenol, Pd nanoparticles

Posted Date: February 3rd, 2022

DOI: https://doi.org/10.21203/rs.3.rs-1311851/v1

License: (a) (i) This work is licensed under a Creative Commons Attribution 4.0 International License. Read Full License 


\section{Abstract}

Enhancing the catalytic activity of supported nanocatalysts is an effective strategy to mitigate costly catalyst separation processes in many industrial processes. In this study, catalytic polysulfone (PS) membranes decorated with in-situ synthesized palladium nanoparticles (PdNPs) were fabricated. The membranes were characterised by SEM, XRD, SAXSpace, FTIR, TEM, AFM, contact angle measurements and EDS. Effect of different amounts of PdNPs on the physicochemical properties, water flux, contact angle and catalytic activity for the reduction of 4-nitrophenol (4-NP) to 4-aminophenol (4-AP) were investigated, and the degradation mechanism proposed. Results showed a uniform dispersion of small $(\sim 5 \mathrm{~nm})$ PdNPs in the membrane. Water flux correlated well with increased membrane porosity which was a function of PdNP loading within the membranes. The Pd loaded membranes showed improved hydrophilicity. Very low PdNP loading (1.0 wt \%) resulted in about $90 \%$ reduction of 4-NP to 4-AP was mainly due to the catalytic effect of PdNPs.

\section{Introduction}

Nanotechnologies based on polymer embedded metal nanoparticles have recently found applications in a wide range of R\&D niches with the focus on enhancing reactivity of the entrapped nanoparticles. Such systems are envisaged to solve a plethora of environmental global challenges, including catalytic degradation of micro-pollutants in water that are otherwise not easily removed by conventional water treatment processes [1][2]. Polymeric membranes can be used as supports for catalytic metal nanoparticles to achieve a mutualistic reactive filtration membrane. Membrane reactors based on the combination of a membrane-based separation and a catalytic chemical reaction in one unit are novel techniques of ensuring process intensification in chemical manufacturing industry. According to SusChem (European Technology Platform for Sustainable Chemistry, Strategic Research Agenda 2005) more than $80 \%$ of the processes in the chemical industry worth approximately $€ 1,500$ billion, depend on catalytic technologies. The integration of catalysis and membrane technologies for process intensification requires the development of new catalytic membrane concepts that can address current barriers related to low flux, high energy consumption, durability and high fouling propensity in catalytic membranes [3].

Catalytic membranes have been used for reductive hydrodehalogenation of contaminants such as pharmaceutical and personal care products, biocides and other emerging organic micropollutants in wastewater [4]. Most reports on membrane entrapped metal nanoparticles are based on pre-synthesis of the nanoparticles followed by their dispersion into the polymer dope solution prior to membrane casting [5]. Particle aggregation and uneven distribution are however inevitable in this blending method [6]. Other techniques such as dip coating [7], slurry filtration, layering, grafting and spin coating [8] suffer the problems of nanoparticle leaching and pore blocking during application. In addition the procedures are often long, laborious and tedious [9]. 
Recently, in-situ generation of the nanoparticles through reduction of appropriate precursors inside the polymer dope solution has been reported as the most convenient and attractive route to the fabrication of metal nanoparticle-embedded polymer membranes. The in-situ nanoparticle generation method offers the advantages of controlled size, shape and distribution of the nanoclusters [10][11][12]. The polymer itself as well as the solvent provides a stabilising effect on the in-situ generated particles. Proper selection of the precursors to facilitate reactions that will generate the desired sizes, shapes and particle distribution within the membrane without compromising the membrane performance is of utmost importance.

A number of studies have reported the in-situ generation of Pd nanoparticles in membranes used mainly for the ligand free Suzuki coupling reactions [13][14], hydrogen generation from the methanolysis of ammonia borane [15] and the Heck reaction of aryl halides under mild conditions [16]. In these reactions, aryl boronic acid and PEG-400 acted as the reducing agents for the in-situ generation of Pd nanoparticles. In a study on microbially produced Pd embedded polyvinylidene fluoride (PVDF) and polysulfone (PSf) membranes, sustained activity for the removal of diatrizoate was reported [17]. Other industrially important reactions where metal loaded catalytic membranes have found applications include: dehydrogenation reactions [18], hydrogenation reactions [19], esterification reactions [20], photocatalytic reactions[21][22] and hydrogen generation reactions [23].

Simple, low cost and highly efficient metal nanoparticle embedded membrane fabrication methodologies still remain elusive due to the incompatibility of the membrane polymeric materials and metal precursor compounds. In addition, harsh chemical treatments tend to degrade the polymer material. Notable attractive features of a successful catalytic membrane include facile recovery and extensive reusability and ease of scale up. Most of the current membrane particle entrapment approaches are prone to catalyst leaching or degradation upon repeated use, thus impairing reaction yields and limiting material reuse [24].

An appropriately designed catalytic membrane reactor in wastewater treatment applications results in improved water quality, high pollutant removal efficiency and reduced downstream separation costs. In this study, a simple in-situ metal entrapment method was developed for the fabrication of Pd entrapped catalytic membrane for the reduction of an organic compound in water. The study helps in understanding the fundamental physicochemical pollutant reduction mechanisms and the relationship between structure, property and performance of the membranes with the aim to fabricate large scale catalytic membranes with improved functionality for the removal of organic pollutants in water.

\section{Experimental \\ 2.1. Materials}

Sodium borohydride, 1-methyl-2-pyrrolidone (NMP) and 4-nitrophenol were purchased from Sigma Aldrich, Germany. Palladium diammine dichloride was purchased from PGM Chemicals, South Africa. 
Polysulfone pellets were supplied by Udel® PSU, Solvay Advanced Polymers. All chemicals were used as received. Deionised water was used for preparation of dye standards and solutions.

\subsection{Membrane synthesis}

Polysulfone in pellet form (18 wt.\%) was dissolved in NMP solution and the solution was stirred until a homogenous solution was obtained. An appropriate amount of $\mathrm{Pd}\left(\mathrm{NH}_{3}\right)_{2} \mathrm{Cl}_{2}$, the Pd precursor, was weighed and added into the polymer solution. The mixture was stirred for $2 \mathrm{~h}$ to obtain solution homogeneity then $\mathrm{NaBH}_{4}(5 \mathrm{mM})$ was added dropwise to facilitate reduction of palladium in the polymer dope solution. The formation of the palladium nanoparticles was observed by a change in the colour of the dope solution from pale yellow to a dark colour. Dope solutions containing different percentages of palladium $(0 \%, 0.05 \%, 0.1 \%, 0.5 \%$ and $1 \% \mathrm{Pd})$ were cast on a clean glass plate using a casting knife with an air gap of $250 \mu \mathrm{m}$. The cast films were immersed into a de-ionised water coagulation bath until the membranes peeled off from the glass plate. The de-ionised water was replaced several times and the membranes were kept in de-ionised water/ethanol mixture until ready for use.

\subsection{Characterisation}

The fabricated membranes were characterised using a number of physico-chemical techniques. FTIR spectra were obtained on a Perkin Elmer (FT-IR Spectrum 100) spectrophotometer using an attenuated total reflectance sample holder. X-ray diffraction (XRD) patterns in the $2 \theta$ range 5 to $80^{\circ}$ were obtained on a Philips PANanalytical X'pert set at $40 \mathrm{kV}$ and $40 \mathrm{~mA}$. Cu Ka radiation $(\lambda=0.15406 \mathrm{~nm})$ was used as the X-ray source. The X-rays were Ni filtered $(0.02 \mathrm{~mm})$ and masked $(11.6 \mathrm{~mm})$ and collimated with Soller slits (0.04 rad). Membrane surface morphologies were analysed on a scanning electron microscopy (SEM) (JEOL JSM - IT300). Membranes were sputter-coated with carbon prior to analysis. TEM analysis was performed on a Tecnai G2 F2O X-Twin MAT equipped with an energy dispersive X-ray spectrometer (EDS). Membrane wettability studies were performed on a Dataphysics contact angle system (Model: OCA20) using de-ionised water as the probe liquid. Measurements were taken at different membranes spots and averaged. Pore morphology and particle distribution and architecture within the membranes were carried out on small angle X-ray scattering equipment (Anton Paar - SAXSpace, GmbH, Germany). The SAXSQuant software ${ }^{\circledR}$ was used to reduce two-dimensional data to one-dimensional intensity versus scattering vector (Q) plots. A $1.5418 \AA$ X-ray was used as the source. The system is equipped with a Dx Cu 12 X04 filament and multilayer X-ray optics. The membrane sample exposure time to the X-ray was 5 times 30 s for both small angle and wide-angle scattering measurements. The measurements were performed normal to the plane of the membrane. Atomic force micrographs of the membranes were obtained from a WITec Alpha 300 atomic force microscope or AFM (WITec, GmbH, Germany). Measurements were performed in non-contact mode using reflex coated FM (AC), $2.8 \mathrm{~N} / \mathrm{m}, 75 \mathrm{kHz}$ AFM Arrow cantilevers. Zeta potentials of the different types of membranes were determined by measurements of streaming potential using a SurPASS Electrokinetic Analyser (Anton Paar GmbH, Austria) with a background electrolyte of $10 \mathrm{mM} \mathrm{KCl}$. The $\mathrm{pH}$ of the working solution was maintained at 5.6. The thermal stability of the materials and its fraction of volatile components were determined by thermogravimetric analysis (PerkinElmer Pyris 1). The specimen was heated from room temperature to 
$900{ }^{\circ} \mathrm{C}$ in a nitrogen atmosphere at the rate of $10^{\circ} \mathrm{C} / \mathrm{min}$ and the changes in weight of the samples was monitored.

\subsection{Flux measurements}

Membrane flux studies were conducted on a six cell Sterlitech Corporation CF042 SS316 cross flow system (Figure 1). The membranes were cut into rectangular pieces of 2.5 by $3.5 \mathrm{~cm}$ to fit into the membrane filtration cells. During fitting, the active layer of the membrane was placed facing downwards. The membranes were then compacted for $2 \mathrm{~h}$ for stabilisation of flux before analysis. De-ionised water was used to measure permeate flux and the flow was kept at a laminar flow. Recording of the permeate flux was done at 3 different operating pressures of 4,7 and 12 bar. The flux was calculated using equation 1:

$$
J_{W}=\frac{V}{t X A}
$$

1

where $J_{w}$ is expressed in $L / m^{2} h, V$ is the volume of water collected for time $t(h)$ time duration using a membrane of area $A\left(\mathrm{~m}^{2}\right)$.

\subsection{Reduction of 4-nitrophenol}

The synthesized membranes were evaluated for their catalytic activity on the reduction of 4-nitrophenol (4-NP) using sodium borohydride as a reducing agent. This reaction was monitored by the use of UV-Vis spectrophotometry. The peak of maximum absorption for 4-nitrophenol appears at $317 \mathrm{~nm}$ and shifts to $400 \mathrm{~nm}$ upon addition of freshly prepared $\mathrm{NaBH}_{4}$ solution due to the formation of 4-nitrophenolate ions under alkaline conditions. Upon addition of Pd/PES membranes, the nitrophenolate peak decreased with time with formation of a new peak at $300 \mathrm{~nm}$, which confirmed the formation of 4-aminophenol (4-AP).

The batch method was employed, in which small pieces of Pd/PES membranes ( 1.0 wt \% Pd) $\left(5 \mathrm{~mm}^{2}, 12\right.$ pieces) were added to the 4-NP solution (100mL, $10 \mathrm{ppm}) . \mathrm{NaBH}_{4}(0.5 \mathrm{M}, 2 \mathrm{~mL})$ solution was then added to the 4-NP and the solution was kept stirring in a three necked flask. Aliquots were sampled at 10 mins intervals for 90 mins and analysed using UV-Vis absorbance. The decrease in intensity of the peak at 400 $\mathrm{nm}$ was monitored as an indication of the reduction of 4-nitrophenol and the formation of 4aminophenol.

\section{Results And Discussion}

\subsection{Charaterisation of the membranes}

SEM was used to investigate the surface morphology of the membranes (Figure 2). Defect free, porous and clean membrane surfaces were observed for all the membranes. The Pd nanoparticles (PdNPs) were not visible in the mixed matrix membrane SEM images. This is similar to a study by Taurozi et al. on in- 
situ embedded silver on a PSF/PVA matrix [25]. However, observable surface morphological changes like the increase in membrane porosity due to an increase in Pd concentrations (wt. \%) was observed. The pure PSf membrane (Figure 2 (a)) showed more apparent and evenly distributed pores with similar pore geometry. With increasing Pd concentrations, the membranes were observed to show increased porosity with evenly distributed and smaller sized pores. The increase in porosity can be attributed to the effects of $\mathrm{Pd}$ nanoparticles as hydrophilic additive influencing the exchange rate between solvent and nonsolvent during phase inversion process [26].

EDS was used to investigate the elemental composition of the membranes. It can be observed that in the pristine PSf membrane (Figure $2(\mathrm{e})$ ), the peaks observed were associated with the elemental components of the polymer which are: $\mathrm{C}, \mathrm{O}$, and S. In Figure 2 (f) additional peaks attributed to the palladium nanoparticles are observed. No other elements were detected in the membrane samples confirming the purity of the fabricated membranes.

TEM images of the $1.0 \mathrm{wt} \%$ Pd/PSf dope solution were observed on a Tecnai G2 F2O X-Twin MAT equipped with an energy dispersive $X$-ray spectrometer (EDS) to investigate the particle size, distribution and elemental composition of the polymer dope solution (Figure 3). PdNPs were evenly dispersed in the polymer dope solution with some aggregation which was reliant on the intensity of the polymer and Pd nanoparticles [27]. The small PdNPs of average size of $5 \mathrm{~nm}$ formed sparsely distributed clusters as observed in Figure 3 (a). The cluster pattern can be described as ballistic cluster-cluster agglomeration. The average size of the Pd nanoparticles as observed on HR-TEM was around $5 \mathrm{~nm}$ (Figure 3(b)) and this concurred with a study done by [28]. The crystallinity of the PdNPs was evaluated through SAED patterns and the polycrystallinity was confirmed as some ringed patterns could be observed (Figure 3 (c)) [29]. The elemental composition of the sample confirmed the presence of peaks attributed to the polymer and the PdNPs: C, O, S and Pd (Figure 3 (d)). However, additional Al and Cu peaks can be attributed to sample holder.

The embedded PdNPs were also analysed by TEM after dissolving the $1.0 \mathrm{wt} \% \mathrm{Pd} / \mathrm{PSf}$ membrane in a solvent. Small pieces of the $1.0 \mathrm{wt} \%$ Pd/PSf membrane were completely dissolved in NMP (2 mL). The solution was sonicated in methanol, dropped on a copper grid, dried and observed on TEM equipped with an energy dispersive X-ray spectrometer (EDS). The PdNPs maintained their morphology after casting and embedding in the PSf membrane. The nanoparticles were evenly distributed in the dissolved membrane solution (Figure 4(a)). Average particle size was around $5 \mathrm{~nm}$ (Figure 4(b)). The SAED pattern showed limited crystallinity due to coverage of the nanoparticles by the polymeric solution. Two ring patterns could be observed (Figure 4 (c)), as opposed to multi ring patterns that are observed in Figure 3 (c). The EDS spectrum confirmed the presence of elements associated with the PSf polymer (C, $\mathrm{O}$ and $\mathrm{S}$ ) as well as the PdNPs (Pd). The presence of $\mathrm{Cu}$ can be attributed to the $\mathrm{Cu}$ grid used during sample analysis.

Atomic force microscopy (AFM) was used to investigate the surface morphology and roughness of the membranes (Figure 5). The bright and dark areas in the images show peaks and valleys of the 
membrane, respectively. The pristine PSf membrane possessed the lowest average roughness (16.56 nm) as shown by the lighter areas in Figure 5(a). In-situ embedding of PdNPs resulted in increased membrane surface area from about $12.69 \mathrm{~nm}$ for the pristine PSf to around 24.59 for the $1.0 \mathrm{wt} \% \mathrm{Pd} / \mathrm{PSf}$ membrane. The increase in membrane surface area due to in-situ embedded PdNPs concurred with the water permeation tests where membranes with higher roughness parameters produced high water flux. According to literature, surface roughness reduces the permeation resistance due to the increased surface area of the membrane [30][31].

The structure of pristine PSf and Pd/PSf membranes were studied by XRD analysis (Figure 6(a)). The insitu generation of PdNPs into PSf membrane did not show any changes in the XRD patterns. The broad peak observed at $2 \theta=16^{\circ}$ can be attributed to the largely amorphous PSf polymer. No obvious PdNPs peaks were observed at higher Pd concentrations. The $1.0 \mathrm{wt} \% \mathrm{Pd} / \mathrm{PSf}$ membrane showed a sharp peak at $2 \theta=14^{\circ}$ and $25^{\circ}$, which may indicate the presence of $P d$ though this could not be confirmed form literature or XRD databases. The XRD pattern for Pd-black should show characteristics peaks at $38.1^{\circ}$ and $46.6^{\circ}$. The absence of Pd peaks can be attributed to the creation of an X-ray shield by the polymer on the in-situ nanoparticles, resulting in low intensity [32][33]. The XRD patterns of the metal nanoparticles embedded in polymeric membranes tend to show shielding of the metal peaks by the polymer phase peaks. The entrapped metal nanoparticles will be completely covered by the polymer phase. In addition, the low percentages of Pd generated in the PSf membranes may have contributed to the low intensities of the Pd peaks.

The water flux increased with increasing amount of in-situ embedded PdNPs (Figure 6(b)). This concurred with the observed increase in the porosity with increasing nanoparticle loading. The water flux also increased with increasing pressure. The $1.0 \mathrm{wt} \% \mathrm{Pd} / \mathrm{PSf}$ membrane showed the highest water flux at 7 bar. The water flux results also corrobarated well with the water contact angle measurements and the roughness parameters calculated from the AFM.

The contact angle is a measure of surface hydrophilicity of the membrane (Figure 6(c)). Pristine PSf showed a water contact angle of $75^{\circ}$. In-situ loading of PdNPs reduced the water contact angle to around $68^{\circ}$ which translates to an improvement in the hydrophilicity of the membranes [34]. Hydrophilic membranes are reported to result in higher water flux due to favourable permeation of water molecules through hydrophilic compared to hydrophobic membranes [35].

The zeta potential of membranes is an important parameter since it represents the membrane surface charge in aqueous solution due to dissociation of functional groups on the membrane surface. All the membranes showed a negative zeta potential at pH 5.6 (Figure 6 (d)). Increasing the concentration of PdNPs in the membranes resulted in more negative surface charges of the membranes. The increasing negative charges would improve the separation efficiency of negatively charged molecules due to the electrostatic repulsion between the negatively charged membrane surface and any negatively charged pollutants [36]. 
The mechanical properties of the membrane were evaluated by using the tensile strength measurements (Table 1). It can be observed that the membrane with the highest Pd concentration (1\% wt.) was able to withstand more tensile stress before permanent deformation. It can be observed that with increase in PdNP concentration, the mechanical properties of the membranes were improved with an elongation at break of $14 \%$ for the $1.0 \mathrm{wt} \% \mathrm{Pd} / \mathrm{PSf}$ compared to only $4 \%$ for the pristine PSf membrane. Similar observations have been reported in literature where the addition of nanoparticles to membranes resulted in improved elongation at break [37]. This is very important in membrane applications where high pressure is required.

Table 1

Mechanical properties of the membranes

\begin{tabular}{|lll|}
\hline Membrane type & Tensile strength $\left(\mathrm{N} / \mathrm{mm}^{2}\right)$ & $\begin{array}{l}\text { Elongation at break } \\
(\%)\end{array}$ \\
\hline PSf & 35 & 4 \\
\hline $0.05 \mathrm{wt} \% \mathrm{Pd} / \mathrm{PSf}$ & 37 & 9 \\
\hline $0.1 \mathrm{wt} \% \mathrm{Pd} / \mathrm{PSf}$ & 38 & 11 \\
\hline $0.5 \mathrm{wt} \% \mathrm{Pd} / \mathrm{PSf}$ & 35 & 13 \\
\hline $1.0 \mathrm{wt} \% \mathrm{Pd} / \mathrm{PSf}$ & 41 & 14 \\
\hline
\end{tabular}

Figure 7 shows thermograms of PSf membranes. The decomposition of PSf and 1.0\% Pd/PSf

membranes followed a similar trend. However, while the decomposition of PSf occurred at $505^{\circ} \mathrm{C}$, that for $1.0 \% \mathrm{Pd} / \mathrm{PSf}$ was observed at $515^{\circ} \mathrm{C}$. This confirmed that membranes containing PdNPs had slightly higher thermal stability than the PSf membrane. The mass losses at temperatures below $130^{\circ} \mathrm{C}$ were due to elimination of adsorbed water [38]. It was also important to note the residual weight at $900{ }^{\circ} \mathrm{C}$ was slightly higher for $1.0 \% \mathrm{Pd} / \mathrm{PSf}$ membrane compared to PSf which completely degraded and resulted in zero residue. The residual weight of $1.0 \% \mathrm{Pd} / \mathrm{PSf}$ membrane confirmed the presence of thermally stable PdNPs. The \% residual mass corresponded to the amount of Pd embedded in the membrane (about $1.0 \%)$.

Small angle X-rays scattering (SAXs) measurements were performed at high resolution to investigate the morphological structure and size distribution of the in-situ synthesized PdNPs. The data obtained from SAXS measurements were analysed using Saxquant software program (Anton Paar, Germany) to generate two-dimensional SAXS patterns. Generalized Indirect Fourier Transformer (GIFT) software was used to convert the two-dimensional SAXS patterns into one dimensional Pair-Distance Distribution Functions (PDDF). In Figure 8, volume distribution of the particle sizes is presented. The particle size of PdNPs can be estimated using Fourier transform based on the scattering vector. The equations used by the Saxquant software to calculate the particle size are expressed in our previous work [22]. 
The volume distribution graphs consist of two symmetrical curves in r-space. The resultant PDDF graphs illustrates that the nanoparticles existed in different sizes (polydisperse) and different shape (polymorphous) due to nucleation and growth stages during in-situ nanoparticle formation. However, the symmetrical nature of the curves demonstrates a normal volume distribution of the nanoparticle size in the membrane. These results concur with the TEM results obtained for nanoparticles in the membrane.

From the SAXS pattern it can be deduced that that the concentration of the nanoparticles in membranes was dilute due to the absence of the q peak (Figure 9). This, therefore, suggests poor electrostatic interactions between the nanoparticles due to extensive interparticle distance. The interparticle distance is approximated by:

$$
d=\frac{2 \Pi}{q_{p e a k}}
$$

2

where $d$ is the interparticle distance and $q$ is the scattering vector [39].

The number distribution of nanoparticle sizes is also an important parameter as it is used to deduce the size of nanoparticles. SAXS intensity (I) of a particle at $\mathrm{q}=0$ can be described by:

$$
\operatorname{Isingle}(q=0)=\left(\Delta P^{2}\right) V^{2}
$$

3

where, $p=$ electron density contrast between the particle and matrix or solvent, $\mathrm{V}=$ particle volume.

For polydisperse system the SAXS intensity at $\mathrm{q}=0$ can be written as:

$$
I(q=0)=N\left(V^{2}\right)(\Delta P)^{2}
$$

4

where, $\mathrm{N}$ is the particle number and $\mathrm{V}^{2}$ is the average volume of these particles. The SAXS intensity at $q=0$ can be obtained by extrapolating SAXS curve to $q=0$ by using Guinear formula. Therefore, the relative particle number distribution can be obtained by comparing SAXS intensities at $q=0$ [40]. The obtained nanoparticle radii were approximately 0.2 to $2 \mathrm{~nm}$ for the $0.05 \mathrm{wt} \% \mathrm{Pd} / \mathrm{PSf}$ membrane and 0.2 to $2.5 \mathrm{~nm}$ for the $0.1,0.5$ and $1.0 \mathrm{wt} \% \mathrm{Pd} / \mathrm{PSf}$ membranes. This signifies that at larger concentrations, the coalescence phase produced bigger nanoparticles meaning the initial concentration of the Pd precursor played a role in the size of the resultant PdNPs. The number distribution indicates that the smaller nanoparticles were more dispersive in the membrane than larger ones.

\subsection{Catalytic reduction of 4-NP}


The reduction of 4-NP to 4-AP was selected as a model reaction for evaluating the catalytic activity of 1.0 wt \% Pd/PSf membrane and the reaction was monitored by UV-Vis spectroscopy. A control experiment was performed using pristine PSF for comparison. The reduction of 4-NP by $\mathrm{NaBH}_{4}$ is thermodynamically feasible because the difference in their standard electrode potentials $\left(\triangle \mathrm{E}^{0}=\mathrm{E}^{0}{ }_{(4-\mathrm{NP} / 4-\mathrm{AP})}-\mathrm{E}^{0}{ }_{(\mathrm{H} 3 \mathrm{BO} / \mathrm{BH} 4)}\right.$ $=-0.76-(-1.33)=0.67 \mathrm{~V})$ is greater than zero, but it could be kinetically restricted in the absence of an efficient catalyst [41]. As soon as the $\mathrm{NaBH}_{4}$ is added, the embedded PdNPs within the membrane initiate the catalytic reduction by relaying the electrons from the donor $\mathrm{BH}_{4}^{-}$to the acceptor 4-NP following their adsorption on the catalyst surface. The role of PdNPs in the redox reactions can be explained in terms of electrochemical current potential [42]. In this case, the rate of electron transfer at the catalyst surface can be influenced by two step mechanism; firstly, adsorption of 4-nitrophenolate ion onto the catalyst surface, then secondly, the interfacial electron transfer and desorption of 4-aminophenolate away from the surface. In the presence of $\mathrm{NaBH}_{4}$, the 4-NP solution exhibits a strong absorption peak at $400 \mathrm{~nm}$ which diminishes with time up to 70 mins as a new peak ascribed to 4-AP appears at approximately $300 \mathrm{~nm}$ (Figure 10 (a)) [43].

Figure 10 Catalytic reduction of 4-NP to 4-AP using a) catalytic $1.0 \mathrm{wt} \% \mathrm{Pd} / \mathrm{PSf}$ membrane b) Pristine PSf membrane c) 4-NP reduction profiles d) Kinetics of the 4-NP reduction. Both reactions were performed under similar conditions ([4-NP] 10 ppm; $\mathrm{NaBH}_{4}, 0.5 \mathrm{M}, 2 \mathrm{~mL} ; 12$ membrane pieces, $5 \mathrm{~mm}^{2}$ of membrane)

The pristine PSf membrane did not show any catalytic activity under the same reaction conditions, even after 100 minutes (Figure 10(b)). It can thus be concluded that, a catalyst is required for the reduction to take place and PSf can be a good support for entrapment of the catalytic PdNPs. Similar observations have been reported elsewhere [44].

Figure 10(c) shows the decrease in the concentration of the 4-NP with time using the $1.0 \mathrm{wt} \% \mathrm{Pd} / \mathrm{PSf}$ membrane. For the control membrane (pristine PSf) no reaction was observed. The kinetics of the reduction reaction was described by Langmuir Hinshelwood pseudo-first order kinetics equation;

$k_{\mathrm{app}} C=-d C / d t$

where $C$ is the concentration of 4-NP at reaction time $t$. A linear correlation was observed between $\ln \left(C / C_{0}\right)$ and the reaction time, confirming pseudo-first order kinetics, and the corresponding $k_{\text {app }}$ values were approximately $2.1 \times 10^{-2} \mathrm{~min}^{-1}$ for the $1.0 \mathrm{wt} \% \mathrm{Pd} / \mathrm{PSf}$ membrane and $1.03 \times 10^{-4} \mathrm{~min}^{-1}$ for the pristine membrane (Figure 9(d)).

The reaction followed pseudo-first order rate law as reported by other researchers [45][46][47]. However, the reaction is much slower than the reported rates in slurry systems. The slow reaction kinetics with embedded nanoparticles can be attributed to the mass flow limitations due to the hinderance of the PdNPs by the PSf membrane phase. Equation 6 shows the reaction between 4-NP and the reducing agent sodium borohydride to form the 4-hydroxylaminophenol $\left(H_{x}\right)$ and then finally 4-AP. 


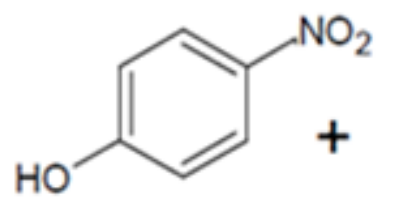

$\mathrm{BH}_{4}{ }^{-}$
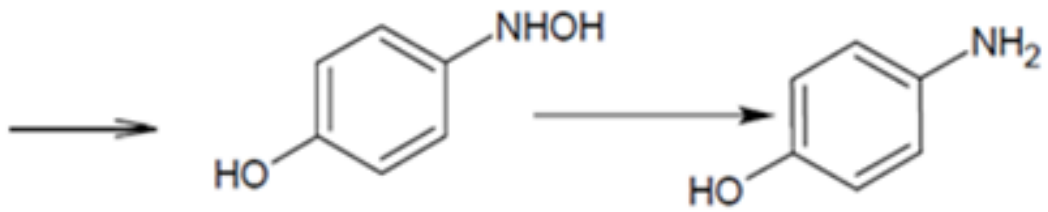

(6)

The reduction of 4-NP to 4-AP follows a series of steps in which 4-NP is reduced to the 4-nitrosophenol and then quickly converted to 4-hydroxylaminophenol $\left(\mathrm{H}_{\mathrm{x}}\right)$, which is the only stable intermediate. Finally, $\mathrm{H}_{\mathrm{x}}$ is reduced to the final product, 4- AP as shown in Figure 11 [48][49][50]. The mechanistic reduction of 4-NP on the PdNPs occurs in two steps that involve (1) diffusion and adsorption of 4-NP to the catalyst surface and (2) electron transfer mediated by the catalyst surface from $\mathrm{NaBH}_{4}$ to the 4-NP. This is then followed by the desorption of products (4-AP) from the surface of catalyst [50][51].

\section{Conclusion}

A simple in-situ precursor reduction and phase inversion method was developed for the fabrication of PdNP embedded PSf membranes for the reduction of 4-NP to 4-AP using $\mathrm{NaBH}_{4}$ as a reducing agent. SEM analysis confirmed that increasing the amount of uniformly dispersed PdNPs improved membrane porosity, resulting in increased membrane water flux. The size and morphology of the embedded PdNPs were confirmed using TEM, which revealed near-spherical particles with an average size of $5 \mathrm{~nm}$. Contact angle measurements revealed improved hydrophilicity, with the value decreasing from $75^{\circ}$ for the pristine PSf membrane to around $68^{\circ}$ for the PdNP embedded membranes. The membranes containing Pd nanoparticles were demonstrated to have slightly higher thermal stability than pristine PSf membranes. The 1\% wt Pd/PSf membrane proved the most efficient membrane for reducing toxic 4-NP to industrially useful 4-AP through a hydride transfer mechanism. The apparent rate constant values were significantly different for Pd/PSf and pristine PSf; $2.1 \times 10^{-2}$ and $1.21 \times 10^{-4} \mathrm{~min}^{-1}$ respectively. With the $\mathrm{k}_{\text {app }}$ value closer to zero, pristine membranes cannot reduce 4-NP. Due to their low cost, sturdiness, and high catalytic effectiveness, PdNP embedded membranes are promising multifunctional materials for practical treatment of industrial wastewater.

\section{Declarations}

\section{Competing interest}

The authors declare that they have no competing interests.

\section{Acknowledgements}


Authors thank the Institute for Nanotechnology and Water Sustainability (iNanoWS) and the University of South Africa (UNISA) for financial support.

\section{Data availability}

The raw/processed data required to reproduce these findings cannot be shared at this time as the data also forms part of an ongoing study.

\section{Funding}

This work was supported by the Institute for Nanotechnology and Water Sustainability, University of South Africa and Rapelang Patala and Nomcebo Khumalo received research support from The University.

\section{Competing Interests}

The authors have no relevant financial or non-financial interests to disclose.

\section{Author Contributions}

All authors contributed to the study conception and design. Material preparation, data collection and analysis were performed by Rapelang Patala and Nomcebo Khumalo. The first draft of the manuscript was written by Rapelang Patala and Nomcebo Khumalo and all authors commented on previous versions of the manuscript. All authors read and approved the final manuscript.

\section{Data Availability}

The datasets generated during and/or analysed during the current study are available from the corresponding author on reasonable request.

\section{References}

1. S.H. Chen, R.M. Liou, C.L. Lai, M.Y. Hung, M.H. Tsai, S.L. Huang, Embedded nano-iron polysulfone membrane for dehydration of the ethanol/water mixtures by pervaporation. Desalination. 234, $221-$ 231 (2008). https://doi.org/10.1016/j.desal.2007.09.089

2. H.S.M. Suhaimi, C.P. Leo, A.L. Ahmad, Preparation and characterization of polysulfone mixed matrix membrane incorporated with palladium nanoparticles in the inversed microemulsion for hydrogen separation. Chem. Eng. Process. Process Intensif. 77, 30-37 (2014).

https://doi.org/10.1016/j.cep.2014.01.004

3. F. Gallucci, J. Antonio Medrano, L. Roses, A. Brunetti, G. Barbieri, J.L. Viviente, Process intensification via membrane reactors, the DEMCAMER project, Processes. 4 (2016) 16

4. H. Cheng, Y. Xie, L.F. Villalobos, L. Song, K.-V. Peinemann, S. Nunes, P.-Y. Hong, Antibiofilm effect enhanced by modification of 1, 2, 3-triazole and palladium nanoparticles on polysulfone membranes. Sci. Rep. 6, 1-12 (2016) 
5. J. Yin, B. Deng, Polymer-matrix nanocomposite membranes for water treatment. J. Memb. Sci. 479, 256-275 (2015). https://doi.org/10.1016/j.memsci.2014.11.019

6. S. Leong, A. Razmjou, K. Wang, K. Hapgood, X. Zhang, H. Wang, TiO2 based photocatalytic membranes: A review. J. Memb. Sci. 472, 167-184 (2014)

7. J. Kim, B. Van Der Bruggen, The use of nanoparticles in polymeric and ceramic membrane structures: Review of manufacturing procedures and performance improvement for water treatment. Environ. Pollut. 158, 2335-2349 (2010). https://doi.org/10.1016/j.envpol.2010.03.024

8. P. Jiang, M.J. McFarland, Large-scale fabrication of wafer-size colloidal crystals, macroporous polymers and nanocomposites by spin-coating. J. Am. Chem. Soc. 126, 13778-13786 (2004)

9. G.E. Romanos, C.P. Athanasekou, V. Likodimos, P. Aloupogiannis, P. Falaras, Hybrid ultrafiltration/photocatalytic membranes for efficient water treatment. Ind. Eng. Chem. Res. 52, 13938-13947 (2013)

10. J. Compton, D. Thompson, D. Kranbuehl, S. Ohl, O. Gain, L. David, E. Espuche, Hybrid films of polyimide containing in situ generated silver or palladium nanoparticles: effect of the particle precursor and of the processing conditions on the morphology and the gas permeability. Polymer 47, 5303-5313 (2006)

11. A. Desforges, R. Backov, H. Deleuze, O. Mondain-Monval, Generation of palladium nanoparticles within macrocellular polymeric supports: application to heterogeneous catalysis of the SuzukiMiyaura coupling reaction. Adv. Funct. Mater. 15, 1689-1695 (2005)

12. Q. Song, D. Xu, W.D. Wang, J. Fang, X. Sun, F. Li, B. Li, J. Kou, H. Zhu, Z. Dong, Ru Clusters Confined in Hydrogen-bonded Organic Frameworks for Homogeneous Catalytic Hydrogenation of N-heterocyclic Compounds with Heterogeneous Recyclability, J. Catal. (2021)

13. D. Saha, K. Chattopadhyay, B.C. Ranu, Aerobic ligand-free Suzuki coupling catalyzed by in situgenerated palladium nanoparticles in water. Tetrahedron Lett. 50, 1003-1006 (2009)

14. W. Han, C. Liu, Z. Jin, Aerobic Ligand-Free Suzuki Coupling Reaction of Aryl Chlorides Catalyzed by In Situ Generated Palladium Nanoparticles at Room Temperature. Adv. Synth. Catal. 350, 501-508 (2008)

15. H. Erdoğan, Ö Metin, S. Özkar, In situ-generated PVP-stabilized palladium (0) nanocluster catalyst in hydrogen generation from the methanolysis of ammonia-borane. Phys. Chem. Chem. Phys. 11, 10519-10525 (2009)

16. W. Han, N. Liu, C. Liu, Z.L. Jin, A ligand-free Heck reaction catalyzed by the in situ-generated palladium nanoparticles in PEG-400. Chinese Chem. Lett. 21, 1411-1414 (2010)

17. T. Hennebel, S. De Corte, L. Vanhaecke, K. Vanherck, I. Forrez, B. De Gusseme, P. Verhagen, K. Verbeken, B. Van der Bruggen, I. Vankelecom, Removal of diatrizoate with catalytically active membranes incorporating microbially produced palladium nanoparticles. Water Res 44, 1498-1506 (2010)

18. G. Li, M. Kanezashi, T. Yoshioka, T. Tsuru, Ammonia decomposition in catalytic membrane reactors: simulation and experimental studies. AIChE J. 59, 168-179 (2013) 
19. N. Wehbe, N. Guilhaume, K. Fiaty, S. Miachon, J.-A. Dalmon, Hydrogenation of nitrates in water using mesoporous membranes operated in a flow-through catalytic contactor. Catal. Today 156, 208-215 (2010)

20. S. Sorribas, A. Kudasheva, E. Almendro, B. Zornoza, Ó de la Iglesia, C. Téllez, J. Coronas, Pervaporation and membrane reactor performance of polyimide based mixed matrix membranes containing MOF HKUST-1. Chem. Eng. Sci. 124, 37-44 (2015)

21. V. Buscio, S. Brosillon, J. Mendret, M. Crespi, C. Gutiérrez-Bouzán, Photocatalytic membrane reactor for the removal of CI Disperse Red 73, Materials (Basel). 8 (2015) 3633-3647

22. A.T. Kuvarega, N. Khumalo, D. Dlamini, B.B. Mamba, Polysulfone/N, Pd co-doped TiO2 composite membranes for photocatalytic dye degradation. Sep. Purif. Technol. 191, 122-133 (2018)

23. D. Jansen, A. de Groot, J.P. Overbeek, J.W. Dijkstra, Y.C. van Delft, M. Saric, Towards application of palladium membrane reactors in large scale production of hydrogen, in: 8th World Congr. Chem. Eng. Montr. Canada, 23-27 Augustus 2009., ECN, 2009

24. E. Hariprasad, T.P. Radhakrishnan, Palladium nanoparticle-embedded polymer thin film "dip catalyst" for Suzuki-Miyaura reaction. ACS Catal 2, 1179-1186 (2012)

25. J.S. Taurozzi, H. Arul, V.Z. Bosak, A.F. Burban, T.C. Voice, M.L. Bruening, V.V. Tarabara, Effect of filler incorporation route on the properties of polysulfone-silver nanocomposite membranes of different porosities. J. Memb. Sci. 325, 58-68 (2008)

26. M. Khajouei, M. Najafi, S.A. Jafari, Development of ultrafiltration membrane via in-situ grafting of nano-GO/PSF with anti-biofouling properties. Chem. Eng. Res. Des. 142, 34-43 (2019)

27. M. López-Viveros, I. Favier, M. Gómez, J.-F. Lahitte, J.-C. Remigy, Remarkable catalytic activity of polymeric membranes containing gel-trapped palladium nanoparticles for hydrogenation reactions, Catal. Today. (2020)

28. P. Strasser, S. Koh, T. Anniyev, J. Greeley, K. More, C. Yu, Z. Liu, S. Kaya, D. Nordlund, H. Ogasawara, Lattice-strain control of the activity in dealloyed core-shell fuel cell catalysts. Nat. Chem. 2, 454-460 (2010)

29. S. Navaladian, B. Viswanathan, T.K. Varadarajan, R.P. Viswanath, A rapid synthesis of oriented palladium nanoparticles by UV irradiation. Nanoscale Res. Lett. 4, 181-186 (2009)

30. S.S. Shahabi, N. Azizi, V. Vatanpour, Tuning thin-film composite reverse osmosis membranes using deep eutectic solvents and ionic liquids toward enhanced water permeation. J. Memb. Sci. 610, 118267 (2020)

31. M.S.S.A. Saraswathi, D. Rana, K. Divya, S. Alwarappan, A. Nagendran, Fabrication of anti-fouling PVDF nanocomposite membranes using manganese dioxide nanospheres with tailored morphology, hydrophilicity and permeation. New J. Chem. 42, 15803-15810 (2018)

32. J.-D. Grunwaldt, N. van Vegten, A. Baiker, Insight into the structure of supported palladium catalysts during the total oxidation of methane, Chem. Commun. (2007) 4635-4637

33. J.C. Crowhurst, A.F. Goncharov, B. Sadigh, J.M. Zaug, D. Aberg, Y. Meng, V.B. Prakapenka, Synthesis and characterization of nitrides of iridium and palladium. J. Mater. Res. 23, 1-5 (2008) 
34. R. Kumar, A.M. Isloor, A.F. Ismail, S.A. Rashid, A. Al Ahmed, Permeation, antifouling and desalination performance of TiO2 nanotube incorporated PSf/CS blend membranes. Desalination. 316, 76-84 (2013)

35. R.S. Hebbar, A.M. Isloor, A.F. Ismail, Contact angle measurements, in: Membr. Charact., Elsevier, 2017: pp. 219-255

36. D. Ji, C. Xiao, S. An, J. Zhao, J. Hao, K. Chen, Preparation of high-flux PSF/GO loose nanofiltration hollow fiber membranes with dense-loose structure for treating textile wastewater. Chem. Eng. J. 363, 33-42 (2019)

37. M. Obaid, N. Ghaffour, S. Wang, M.-H. Yoon, I.S. Kim, Zirconia nanofibers incorporated polysulfone nanocomposite membrane: Towards overcoming the permeance-selectivity trade-off. Sep. Purif. Technol. 236, 116236 (2020)

38. L. Jacob, S. Joseph, L.A. Varghese, Polysulfone/MMT mixed matrix membranes for hexavalent chromium removal from wastewater. Arab. J. Sci. Eng. 45, 7611-7620 (2020)

39. A. Ortiz-Negrón, D. Suleiman, The effect of T i 02 nanoparticles on the properties of sulfonated block copolymers, J. Appl. Polym. Sci. 132 (2015)

40. S. Yan, Z. Wu, H. Yu, Y. Gong, Y. Tan, R. Du, W. Chen, X. Xing, G. Mo, Z. Chen, Time-resolved smallangle X-ray scattering study on the growth behavior of silver nanoparticles. J. Phys. Chem. C 118, 11454-11463 (2014)

41. B. Baruah, G.J. Gabriel, M.J. Akbashev, M.E. Booher, Facile synthesis of silver nanoparticles stabilized by cationic polynorbornenes and their catalytic activity in 4-nitrophenol reduction. Langmuir. 29, 4225-4234 (2013)

42. P.L. Freund, M. Spiro, Colloidal catalysis: the effect of sol size and concentration. J. Phys. Chem. 89, 1074-1077 (1985)

43. Y. Zhu, W.D. Wang, X. Sun, M. Fan, X. Hu, Z. Dong, Palladium nanoclusters confined in MOF@ COP as a novel nanoreactor for catalytic hydrogenation. ACS Appl. Mater. Interfaces. 12, 7285-7294 (2020)

44. Q. Song, W.D. Wang, K. Lu, F. Li, B. Wang, L. Sun, J. Ma, H. Zhu, B. Li, Z. Dong, Three-dimensional hydrophobic porous organic polymers confined $\mathrm{Pd}$ nanoclusters for phase-transfer catalytic hydrogenation of nitroarenes in water. Chem. Eng. J. 415, 128856 (2021)

45. S. Wunder, F. Polzer, Y. Lu, Y. Mei, M. Ballauff, Kinetic analysis of catalytic reduction of 4-nitrophenol by metallic nanoparticles immobilized in spherical polyelectrolyte brushes. J. Phys. Chem. C 114, 8814-8820 (2010). https://doi.org/10.1021/jp101125j

46. M. Nemanashi, R. Meijboom, Synthesis and characterization of $\mathrm{Cu}, \mathrm{Ag}$ and $\mathrm{Au}$ dendrimerencapsulated nanoparticles and their application in the reduction of 4-nitrophenol to 4-aminophenol. J. Colloid Interface Sci. 389, 260-267 (2013)

47. N. Bingwa, R. Patala, J.-H. Noh, M.J. Ndolomingo, S. Tetyana, S. Bewana, R. Meijboom, Synergistic Effects of Gold-Palladium Nanoalloys and Reducible Supports on the Catalytic Reduction of 4Nitrophenol, Langmuir. 33 (2017). https://doi.org/10.1021/acs.langmuir.7b00903 
48. R.D. Neal, Y. Inoue, R.A. Hughes, S. Neretina, Catalytic reduction of 4-nitrophenol by gold catalysts: the influence of borohydride concentration on the induction time. J. Phys. Chem. C 123, 1289412901 (2019)

49. Y.S. Seo, E.-Y. Ahn, J. Park, T.Y. Kim, J.E. Hong, K. Kim, Y. Park, Y. Park, Catalytic reduction of 4nitrophenol with gold nanoparticles synthesized by caffeic acid. Nanoscale Res. Lett. 12, 1-11 (2017)

50. S. Gu, Y. Lu, J. Kaiser, M. Albrecht, M. Ballauff, Kinetic analysis of the reduction of 4-nitrophenol catalyzed by Au/Pd nanoalloys immobilized in spherical polyelectrolyte brushes. Phys. Chem. Chem. Phys. 17, 28137-28143 (2015)

51. K. Sravanthi, D. Ayodhya, P.Y. Swamy, Green synthesis, characterization and catalytic activity of 4nitrophenol reduction and formation of benzimidazoles using bentonite supported zero valent iron nanoparticles. Mater. Sci. Energy Technol. 2, 298-307 (2019)

\section{Figures}

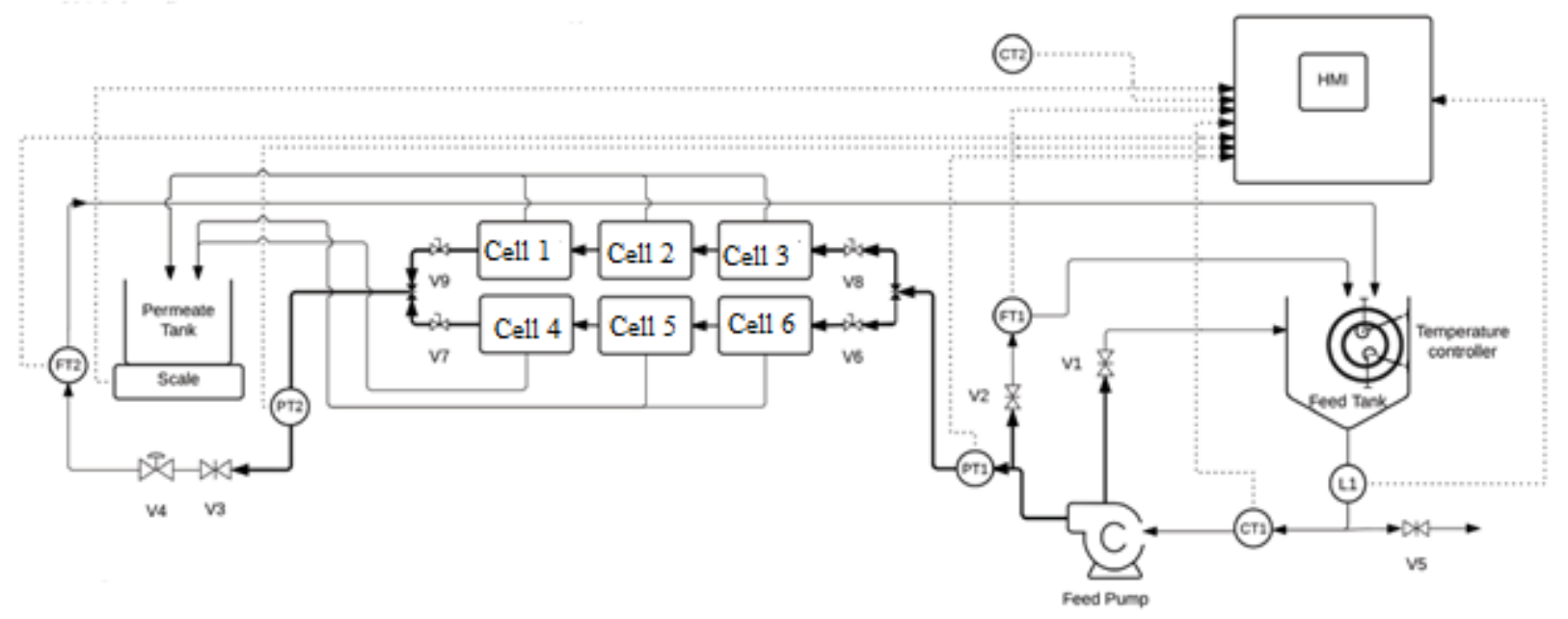

Figure 1

Schematic of the crossflow membrane filtration system $[V=$ Valve, $\mathrm{PT}=$ Pressure transmitter, $\mathrm{FT}=\mathrm{Flow}$ rate transmitter, $\mathrm{CT}=$ Conductivity/Temperature transmitter] 


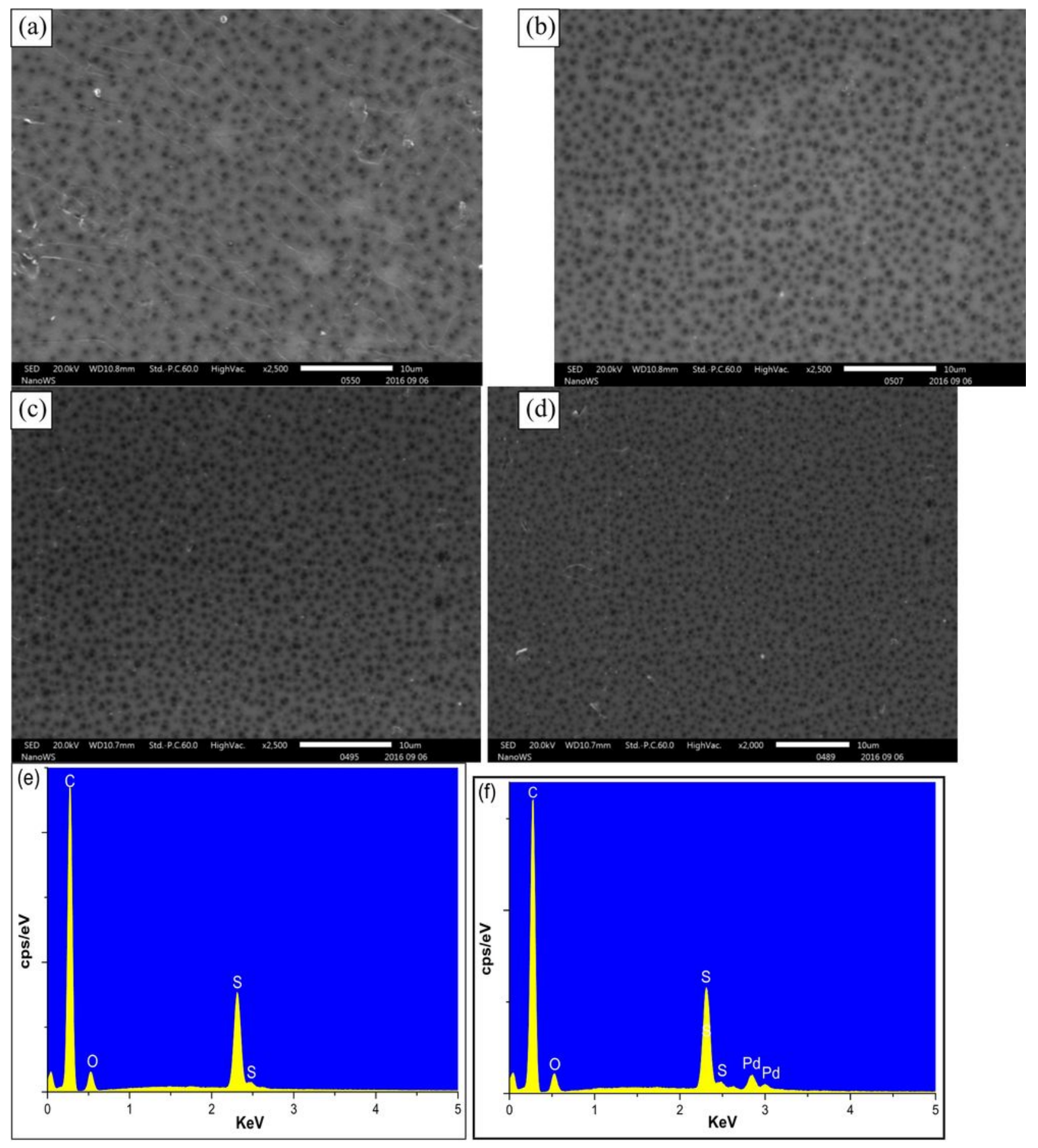

\section{Figure 2}

SEM images of membrane surfaces of a) Pure PSf (b) $0.1 \% \mathrm{Pd} / \mathrm{PSf}$ (c) $0.5 \% \mathrm{Pd} / \mathrm{PSf}$ (d) $1.0 \% \mathrm{Pd} / \mathrm{PSf}$ and EDS spectra of (e) PSf membrane (f) $1.0 \% \mathrm{Pd} / \mathrm{PSf}$ 

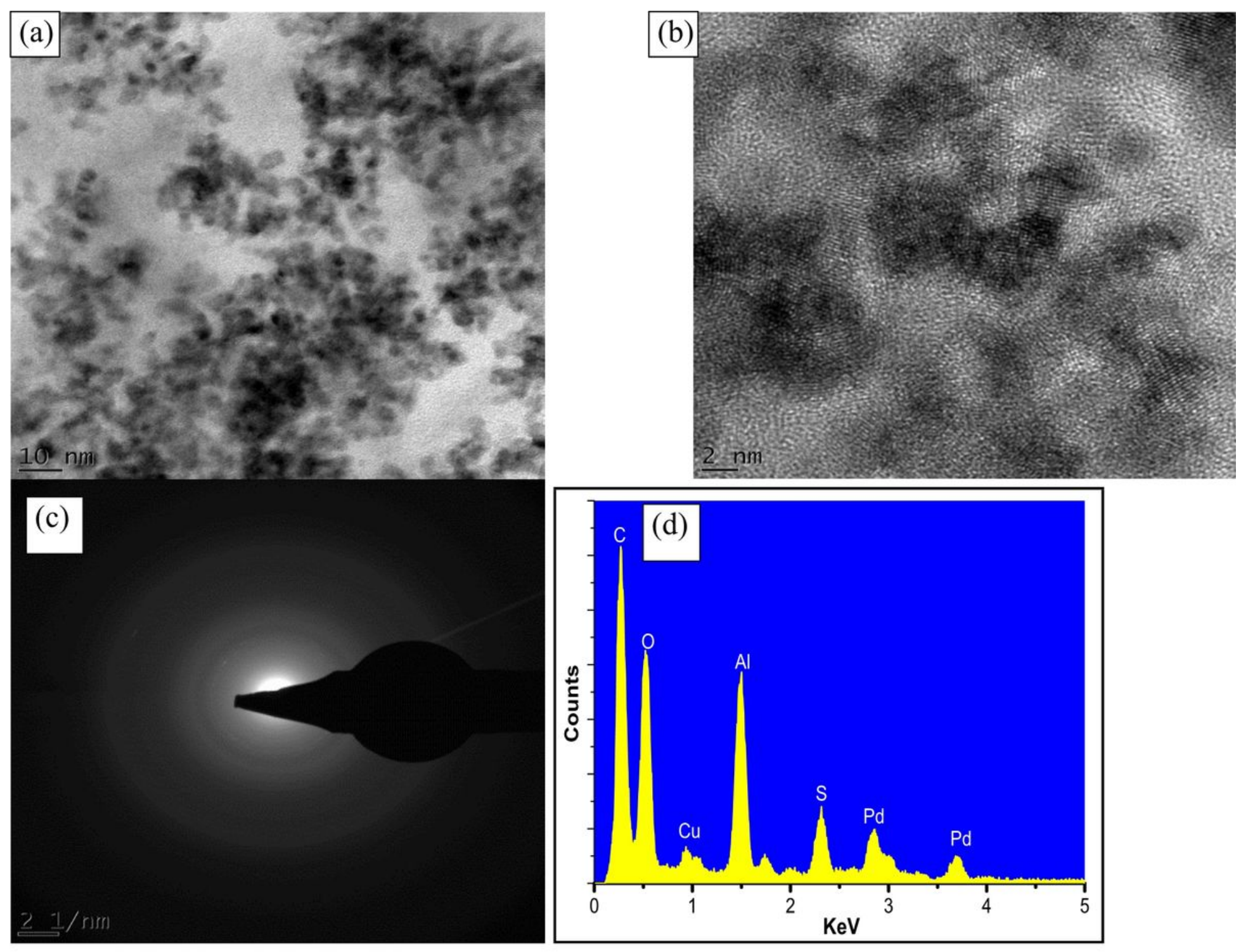

Figure 3

(a) TEM, (b) HR-TEM, (c) SAED and (d) EDS results of $1.0 \mathrm{wt} \% \mathrm{Pd} / \mathrm{PSf}$ dope polymer solution 

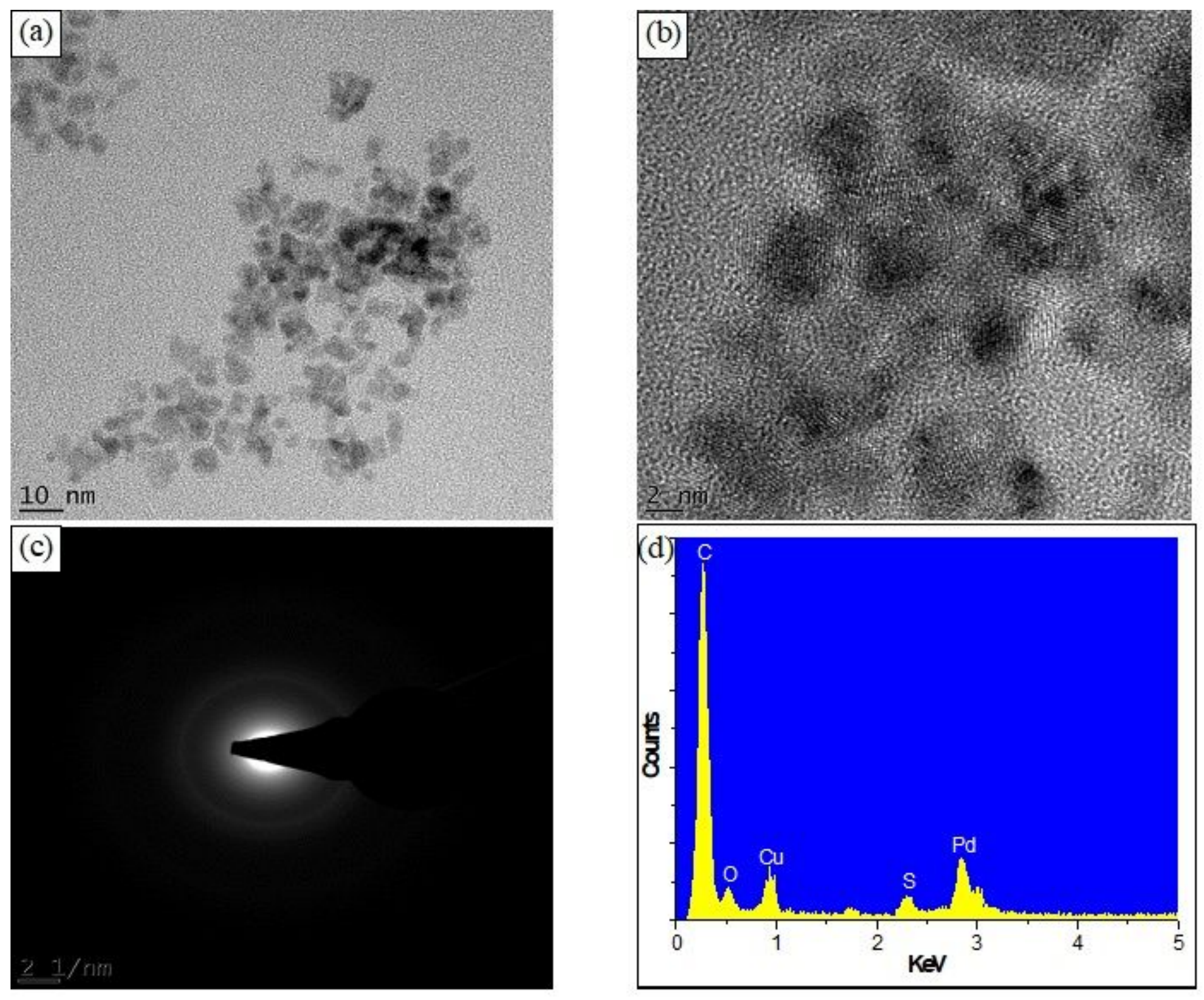

Figure 4

(a) TEM, (b) HR-TEM, (c) SAED and (d) EDS results of the disssolved 1.0 wt \% Pd/PSf membrane 

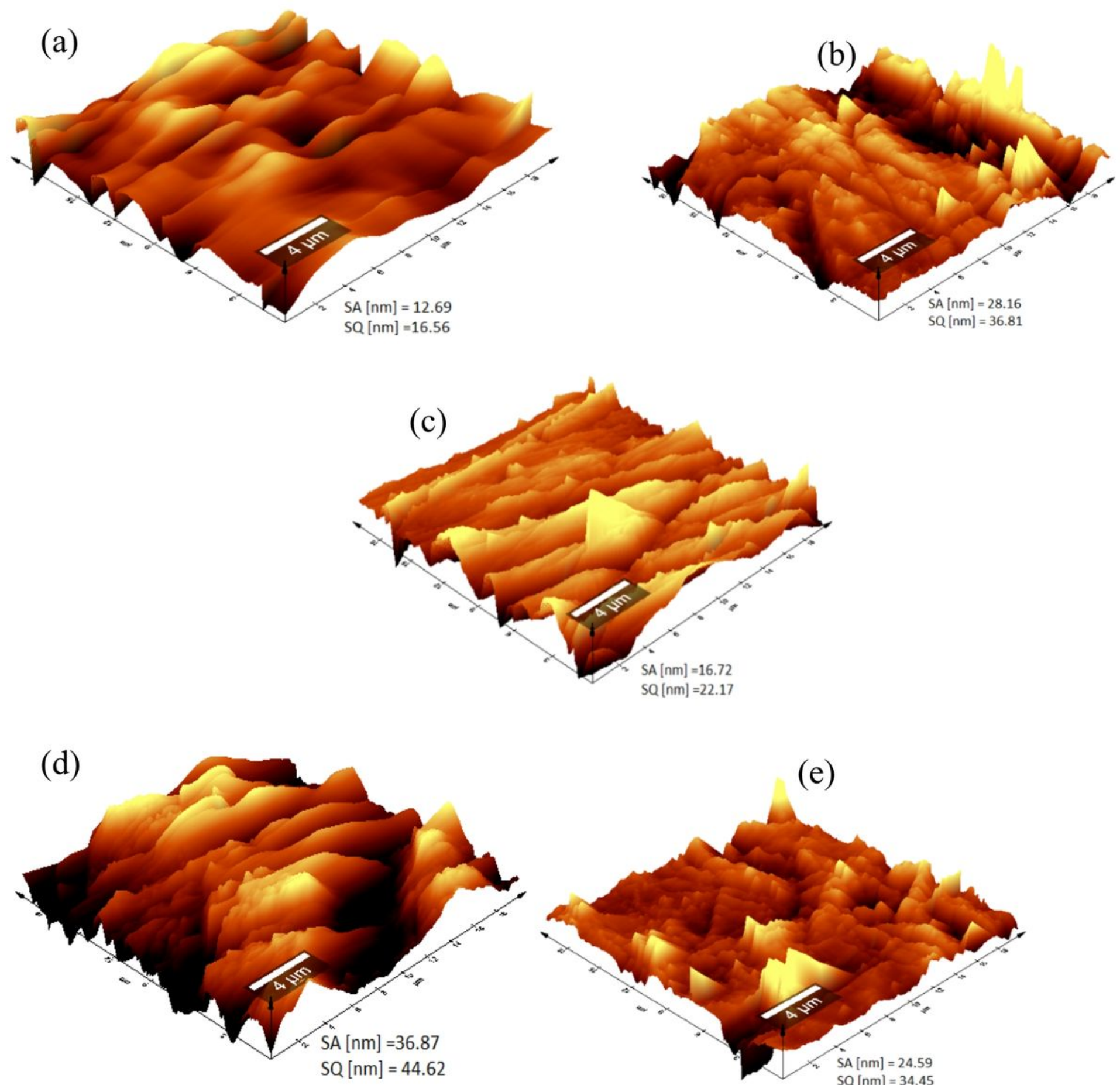

(e)

\section{Figure 5}

AFM images of the membranes: (a) Pristine PSf, (b) $0.05 \%$ Pd/PSf, (c) $0.1 \%$ Pd/PSf, (d) $0.5 \%$ Pd/PSf (e) $1 \% \mathrm{Pd} / \mathrm{PSf}$ 

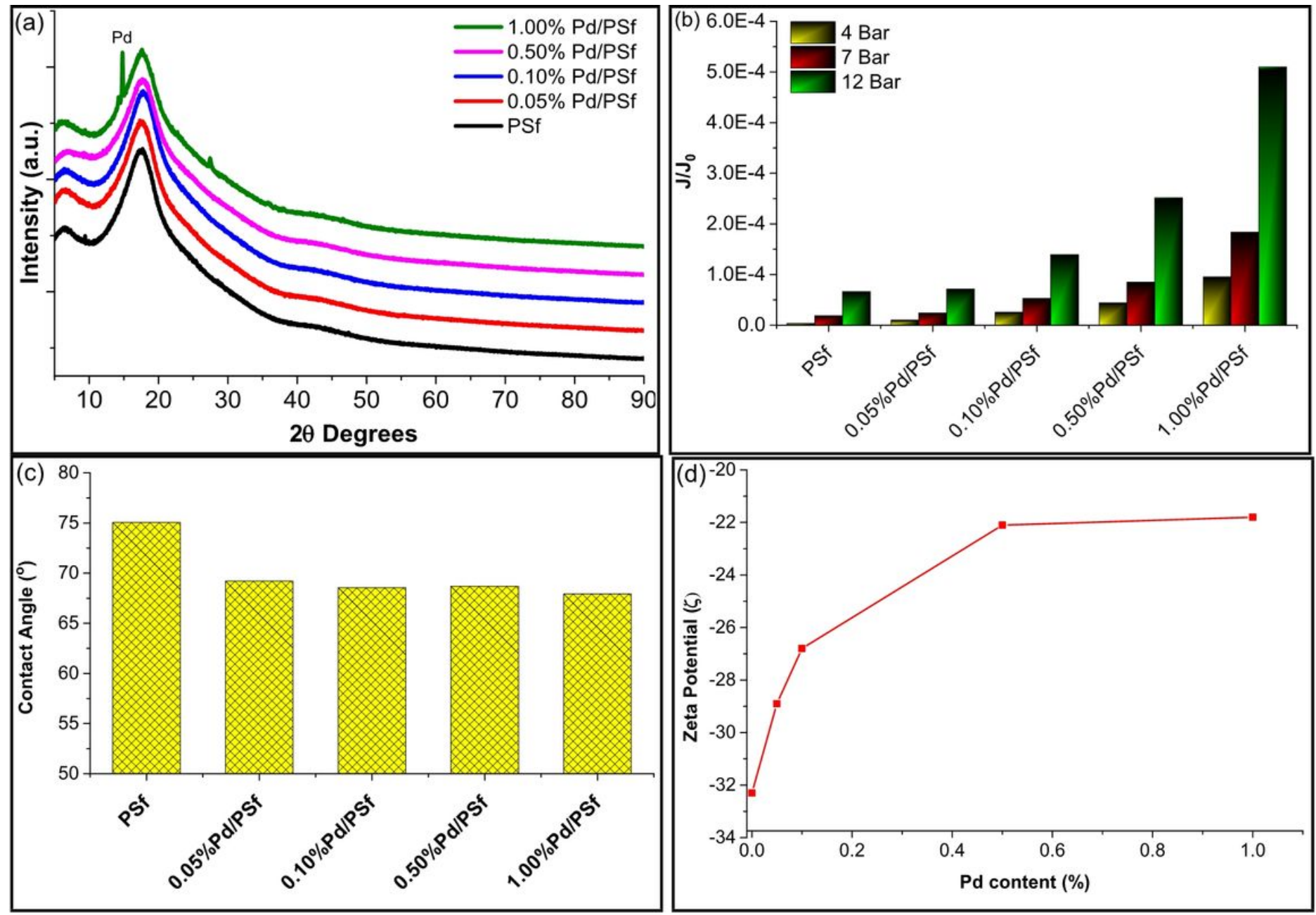

\section{Figure 6}

(a) XRD spectra (b) Water flux measurements of the membranes at different pressures (c) Contact angle values and (d) Zeta potential values of the membranes at $\mathrm{pH}=5.6$ 


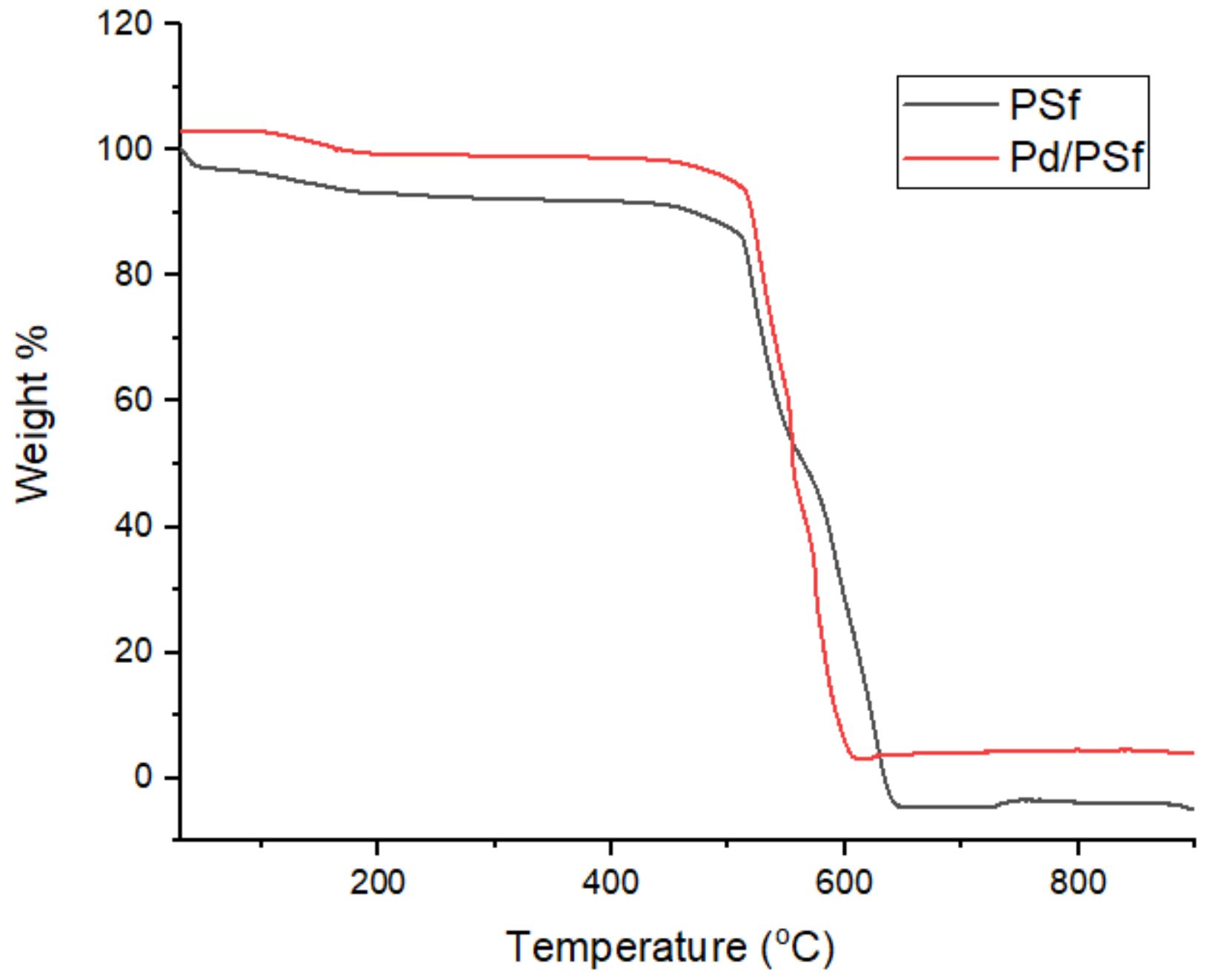

Figure 7

TGA for pristine PSf and 1.0\% Pd/PSf membranes 

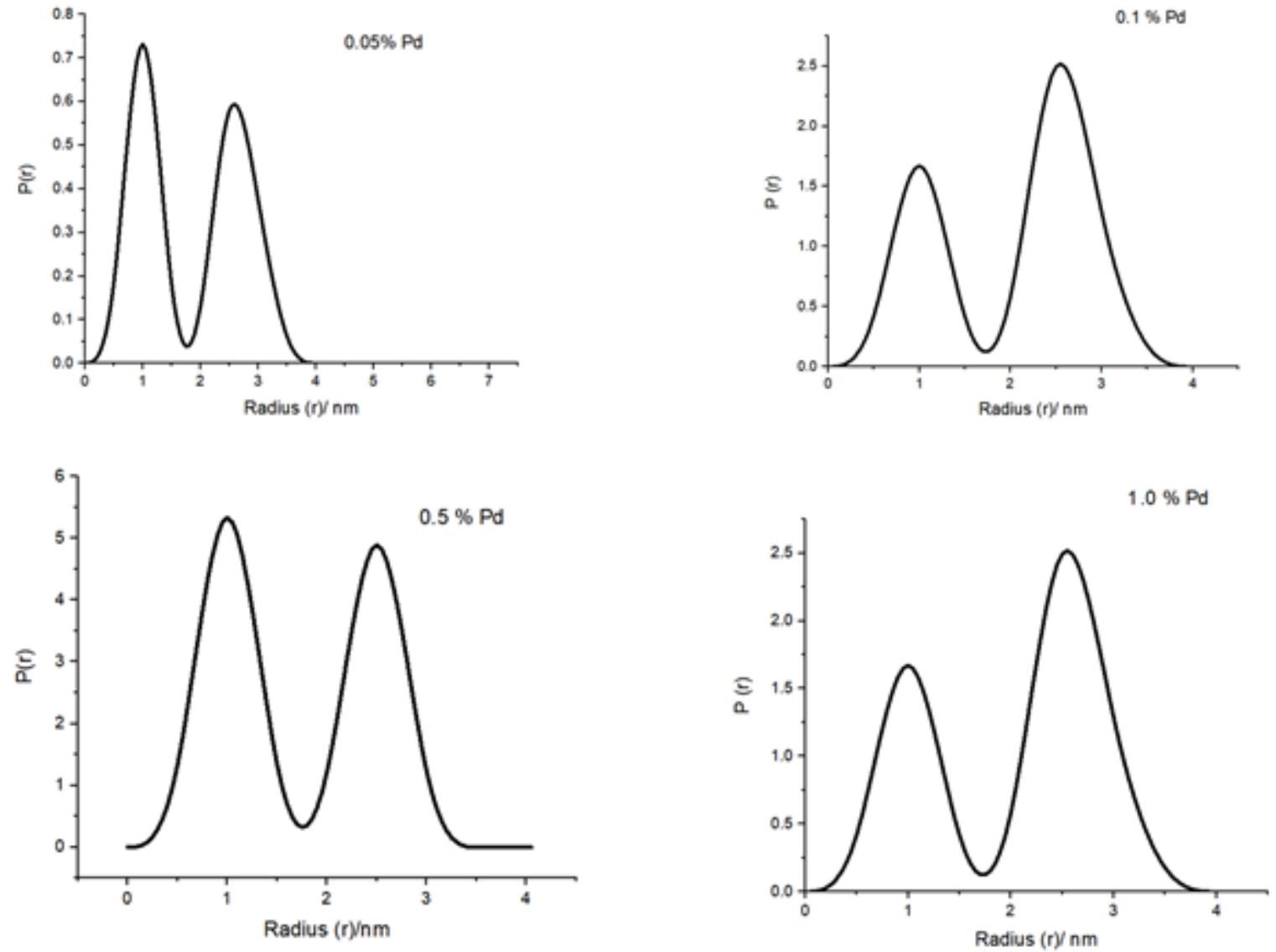

Figure 8

Volume distribution of the in situ synthesized Pd nanoparticles (a) $0.05 \mathrm{wt} \% \mathrm{Pd} / \mathrm{PSf}$ (b) $0.1 \mathrm{wt} \% \mathrm{Pd} / \mathrm{PSf}$, (c) $0.5 \mathrm{wt} \% \mathrm{Pd} / \mathrm{PSf}$ and (d) $1.0 \mathrm{wt} \% \mathrm{Pd} / \mathrm{PSf}$ 

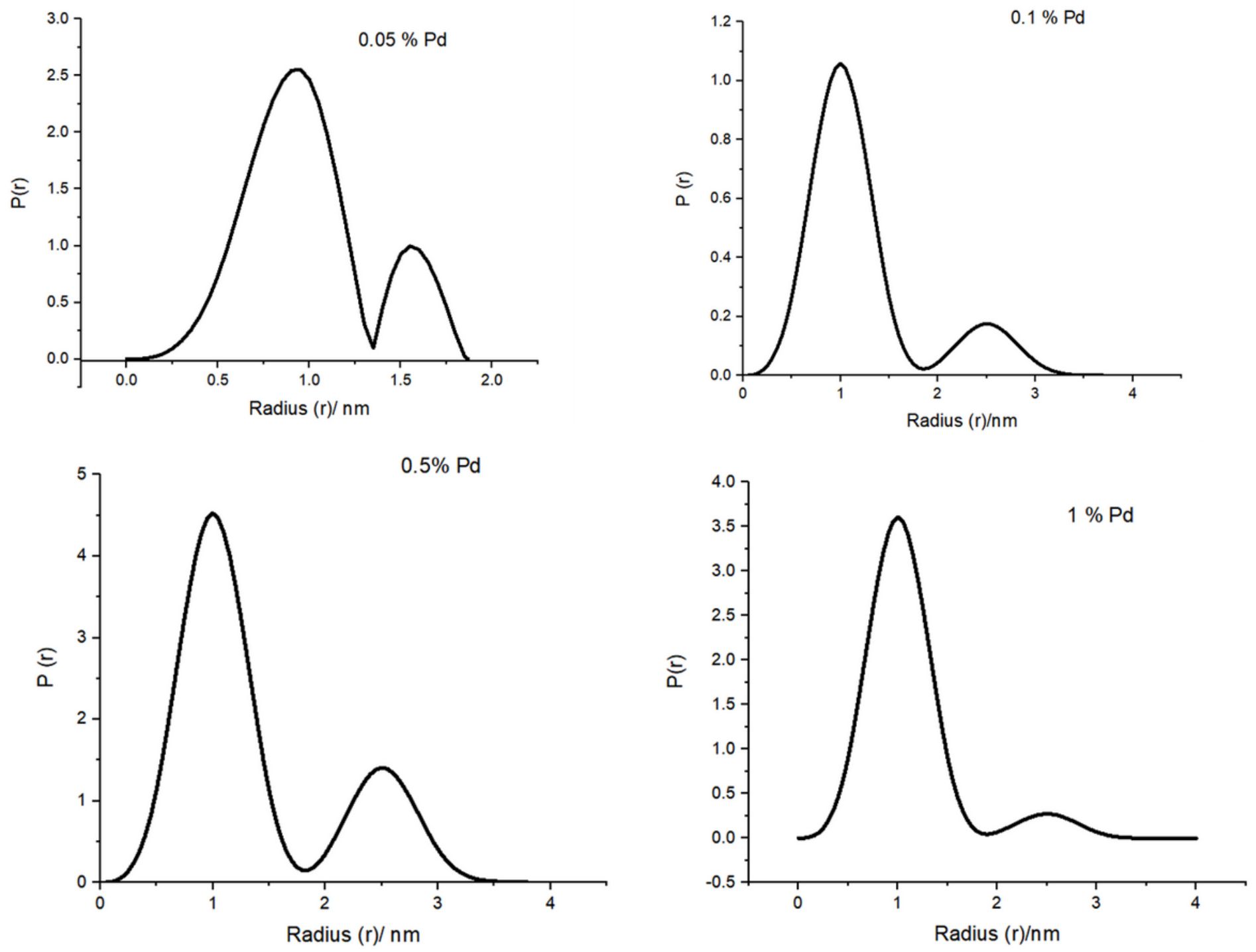

Figure 9

Number distribution of the in-situ synthesized PdNPs (a) 0.05 wt \% Pd/PSf, (b) 0.1 wt \% Pd/PSf, (c) 0.5 wt Pd/PSf and (d) 1.0 wt \% Pd/PSf 

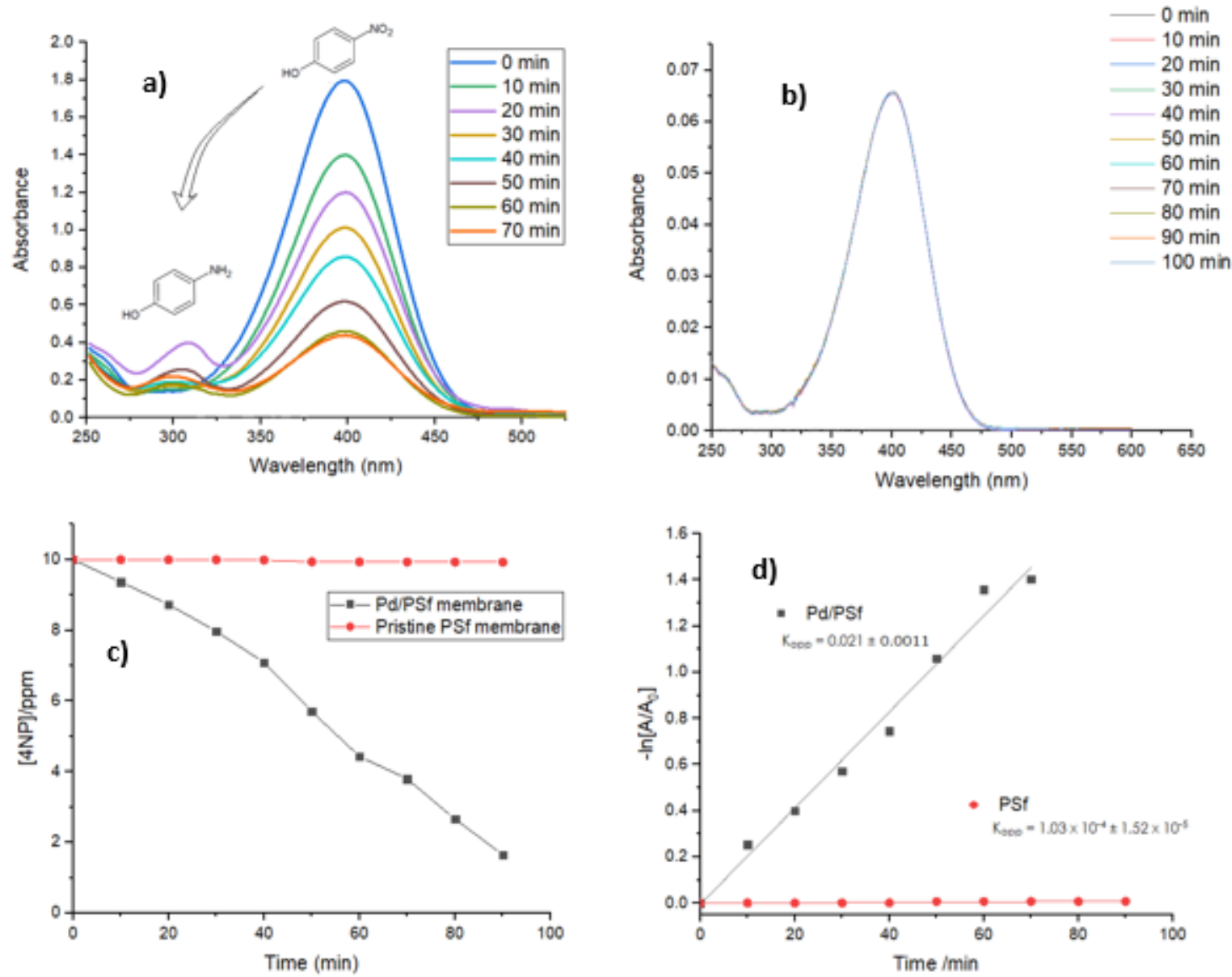

Figure 10

Catalytic reduction of 4-NP to 4-AP using a) catalytic $1.0 \mathrm{wt} \%$ Pd/PSf membrane b) Pristine PSf membrane c) 4-NP reduction profiles d) Kinetics of the 4-NP reduction. Both reactions were performed under similar conditions ([4-NP] 10 ppm; $\mathrm{NaBH}_{4}, 0.5 \mathrm{M}, 2 \mathrm{~mL} ; 12$ membrane pieces, $5 \mathrm{~mm}^{2}$ of membrane) 

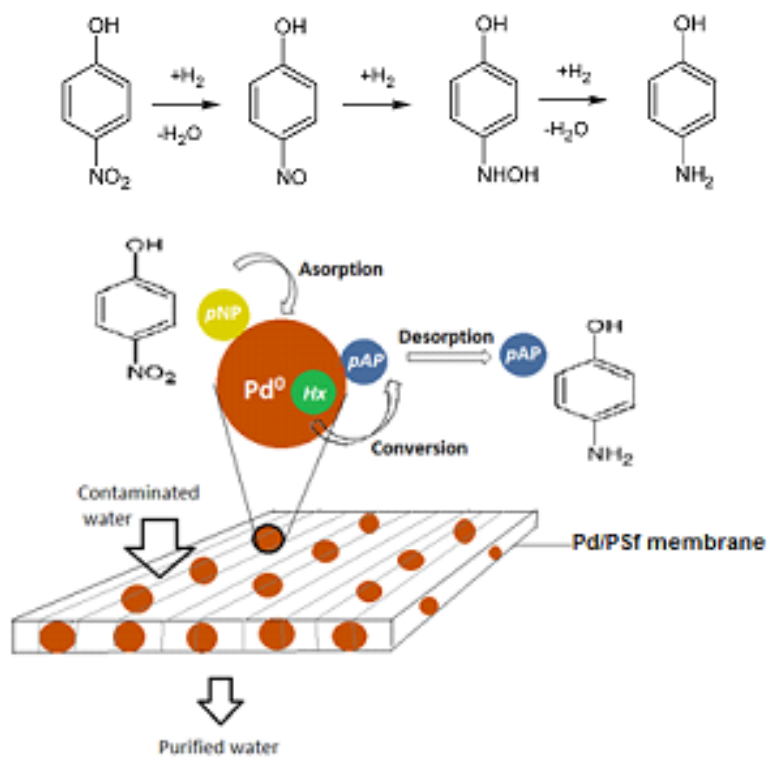

\section{Figure 11}

Proposed scheme for the reduction of 4-NP to 4-AP by Pd/PSf membranes 